\title{
Prevalencia de hidronefrosis en mujeres con prolapso de órganos pélvicos avanzado
}

\section{Prevalence of hydronephrosis in women with advanced pelvic organ prolapse}

\author{
Imelda Magdalena Miranda-Mazariegos, Patricia Inés Velázquez-Castellanos, Nancy Godoy-Rodríguez, Rogelio \\ de Jesús Orozco-Cantellanos
}

\begin{abstract}
Resumen
ANTECEDENTES: El prolapso de órganos pélvicos es una alteración frecuente en mujeres posmenopáusicas y multíparas. La hidronefrosis es una complicación importante del prolapso urogenital.

OBJETIVO: Estimar la prevalencia de hidronefrosis en mujeres con prolapso de órganos pélvicos avanzado.

MATERIALES Y MÉTODOS: Estudio observacional, descriptivo y longitudinal, efectuado en mujeres con prolapso de órganos pélvicos grados III y IV, a quienes se realizó ecografía renal para detectar hidronefrosis y programarlas para corrección quirúrgica del prolapso urogenital. Se determinó la concentración de azoados pre y posquirúrgicos, con la finalidad de evaluar la curación de la hidronefrosis. Para el análisis estadístico se utilizaron las pruebas t de Student y exacta de Fisher. Se consideró estadísticamente significativo el valor de $\mathrm{p}<0.05$.

RESULTADOS: Se registraron 40 pacientes. La prevalencia de hidronefrosis fue de $22.5 \%$. Las pacientes posmenopáusicas, multíparas y con obesidad tuvieron mayor riesgo de prolapso de órganos pélvicos. Después del tratamiento quirúrgico desapareció totalmente la hidronefrosis en $78 \%$ de los casos.

CONCLUSIONES: La corrección del prolapso de órganos pélvicos avanzado mediante intervención quirúrgica es una estrategia efectiva en pacientes con hidronefrosis. La ecografía renal es un estudio útil para establecer el diagnóstico y tratamiento oportunos de hidronefrosis provocada por un prolapso de órganos pélvicos.
\end{abstract}

PALABRAS CLAVE: Hidronefrosis; prolapso de órganos pélvicos; ecografía renal.

Abstract

BACKGROUND: Pelvic organ prolapse is a frequent alteration in postmenopausal and multiparous women. Hydronephrosis is an important complication of urogenital prolapse.

OBJECTIVE: To determine the prevalence of hydronephrosis in women with advanced pelvic organ prolapse.

MATERIALS AND METHODS: An observational, descriptive, longitudinal study was conducted on women with grade III and IV pelvic organ prolapse that had kidney ultrasound study to detect hydronephrosis and were then programmed for surgical treatment to correct the urogenital prolapse. The preoperative and postoperative concentrations of serum creatinine, serum urea, and serum blood urea nitrogen were determined to evaluate hydronephrosis cure. The Student's t test and Fisher's exact test were employed for the statistical analysis and statistical significance was set at a $p<0.05$.

RESULTS: Forty patients were registered. The prevalence of hydronephrosis was $22.5 \%$. Postmenopausal, multipara women with obesity had greater risk for pelvic organ prolapse. Hydronephrosis disappeared completely after surgical treatment in $77.7 \%$ of the cases.

CONCLUSIONS: The correction of advanced pelvic organ prolapse through surgical intervention is an effective strategy in patients with hydronephrosis. Kidney ultrasound is a useful method for diagnosing hydronephrosis caused by pelvic organ prolapse and performing its opportune treatment.

KEYWORDS: Hydronephrosis; Pelvic organ prolapse; Kidney ultrasound
Unidad de Urología Ginecológica y Cirugía Pélvica Reconstructiva, Antiguo Hospital Civil de Guadalajara Fray Antonio Alcalde, Guadalajara, Jalisco, México.

Recibido: febrero 2018

Aceptado: mayo 2018

Correspondencia Imelda Magdalena Miranda Mazariegos imeldamiranda20@hotmail.com

Este artículo debe citarse como Miranda-Mazariegos IM, VelázquezCastellanos PI, Godoy-Rodríguez N, Orozco-Cantellanos RJ. Prevalencia de hidronefrosis en mujeres con prolapso de órganos pélvicos avanzado. Rev Mex Urol. 2018 mayo-junio;78(3):197-201. DOI:https://doi.org/10.24245/revmexurol.v78i3.1973 


\section{ANTECEDENTES}

El prolapso genital es el descenso o desplazamiento de los órganos pélvicos a través de la vagina y en dirección a la vulva, provocado por la alteración de las estructuras que dan soporte y sostén, y de la musculatura e inervación del sistema urinario e intestinal. El prolapso se considera una hernia visceral, situada en un punto débil del piso pélvico (como el hiato urogenital), que puede generar una enfermedad multisistémica, que debe tratarse con un enfoque multidisciplinario, para de esta forma reparar la disfunción del piso pélvico, frecuentemente acompañada de cistocele, rectocele, o ambos. ${ }^{1}$ El prolapso de órganos pélvicos es una complicación importante de la disfunción del piso pélvico, incluso puede asociarse con diversos síntomas de disfunción urinaria. Algunos estudios señalan que el prolapso de órganos pélvicos provoca uropatía obstructiva, lo que resulta en hidronefrosis. ${ }^{2,3}$

El prolapso de órganos pélvicos es una alteración que afecta a millones de mujeres conforme aumenta la edad. La prevalencia exacta es difícil de determinar, pues influyen razones como: 1) utilizar diferentes sistemas de clasificación para establecer el diagnóstico, 2) variación de los estudios en función de la manifestación o no de síntomas y 3 ) desconocimiento actual de la cantidad de mujeres que no acuden a consulta. ${ }^{1,4-6}$ En Estados Unidos se realizan 200,000 cirugías para el tratamiento del prolapso de órganos pélvicos anualmente, con un riesgo estimado de $12.6 \%$ de requerir el procedimiento quirúrgico en algún momento de la vida. ${ }^{4}$

Entre los diversos factores de riesgo predisponentes al prolapso de órganos pélvicos se encuentran: parto, posmenopausia, aumento de la presión abdominal de forma crónica por neumopatías, levantamiento de objetos pesados, estreñimiento crónico, obesidad y antecedente de cirugía pélvica. ${ }^{7}$ Es importante comprender la fisiopatología y los factores de riesgo asociados con el prolapso genital, con la finalidad de prevenir su aparición y las complicaciones asociadas.

La prevalencia de hidronefrosis en pacientes con prolapso de órganos pélvicos varía de 7 a $17 \% .{ }^{8,9}$ Esta alteración se relaciona y aumenta significativamente con la gravedad del prolapso (los casos de hidronefrosis severa son excepcionales). La hidronefrosis en pacientes con prolapso de órganos pélvicos se origina por la angulación de los uréteres, en mujeres con prolapso avanzado por compresión extrínseca del útero y en quienes sufren prolapso de la bóveda vaginal se debe al debilitamiento y desintegración de los ligamentos cardinales poshisterectomía. 1,9-11

Debido a las limitaciones de algunos métodos de imagen, como la gammagrafía renal, resonancia magnética y tomografía computada, la atención se ha centrado en la ecografía, pues permite identificar la hidronefrosis con mayor rapidez y facilidad en pacientes con prolapso de órganos pélvicos. ${ }^{1,12}$

La hidronefrosis puede evolucionar a insuficiencia renal aguda y subsecuentemente a insuficiencia crónica si no se trata de forma oportuna. Aunque la hidronefrosis es una de las complicaciones más importantes del prolapso urogenital, suele corregirse mediante intervención quirúrgica y revertirse espontáneamente en la mayoría de los casos.

El objetivo de este estudio fue estimar la prevalencia de hidronefrosis en mujeres con prolapso de órganos pélvicos avanzado y su proceso de recuperación.

\section{MATERIALES Y MÉTODOS}

Estudio observacional, descriptivo y longitudinal llevado a cabo en el servicio de Urología ginecológica del Hospital Civil de Guadalajara Fray 
Antonio Alcalde. Criterios de inclusión: mujeres mayores de edad, con diagnóstico de prolapso de órganos pélvicos avanzado (POP-Q grado III y IV). Criterios de exclusión: pacientes que no firmaron el consentimiento informado y quienes tuvieran otro tipo de tratamiento no quirúrgico que influyera en el resultado, como la aplicación de pesarios.

A todas las pacientes se les realizó historia clínica, exploración física y ginecológica, valoración prequirúrgica y ecografía renal, según el protocolo de la institución. Del mismo modo, todas fueron valoradas por un especialista en cirugía ginecológica y piso pélvico para realizar los procedimientos quirúrgicos. Después de la cirugía se llevó a cabo el seguimiento clínico, en el posoperatorio inmediato intrahospitalario y en consulta externa a los 8, 21, 45 y 90 días posquirúrgicos. Al término de este periodo se solicitó a las pacientes con antecedente de hidronefrosis la ecografía renal de control.

Los datos obtenidos se analizaron y procesaron en el programa Excel, SPSS (Statistical Package for the Social Sciences) versión 20, y en el Programa de Estadísticas Epidemiológicas de Código Abierto para Salud Pública (OpenEpi) versión 3.01.13 Se utilizó estadística descriptiva, mediante medidas de tendencia central (media, mediana, desviación estándar y porcentaje) para variables numéricas, frecuencias y proporciones para variables categóricas, además de la estimación de la asociación de riesgo (RM). Las variables independientes con distribución normal se examinaron con la t Student y la prueba exacta de Fisher. Se consideró estadísticamente significativo el valor de $\mathrm{p}<0.05$.

\section{RESULTADOS}

Se registraron 40 pacientes con edad media de 65 años (límites 42-83 años; \pm 10.48 DE): 34 fueron multíparas y 6 tuvieron antecedente de dos partos (7.08 $\pm 3.2 \mathrm{DE})$. En cuanto al índice de masa corporal (IMC) se reportó una media de $27.97 \mathrm{~m}^{2}$ (límites 22-36 m²; \pm 5.31 ). De acuerdo con la clasificación del IMC de la OMS, 15\% tuvo peso normal, $47.5 \%$ sobrepeso y $37.5 \%$ obesidad.

De las 40 pacientes estudiadas, 25 se clasificaron con prolapso de órganos pélvicos avanzado (POPQ) grado III (con 4 casos de hidronefrosis) y 15 con POP-Q grado IV (con 5 casos de hidronefrosis).

La prevalecía de hidronefrosis en pacientes con prolapso de órganos pélvicos fue de $22.5 \%$. Se reportaron 6 pacientes con hidronefrosis bilateral, 1 con hidronefrosis unilateral derecha y 2 con hidronefrosis unilateral izquierda (Cuadro 1).

El riesgo relativo $(\mathrm{RR})$ de padecer hidronefrosis en pacientes con POP-Q grado IV versus POP-Q grado III fue de 2.6. En cuanto a las mujeres con POP-Q grado IIIC versus POP-Q grados III Aa y Ba, se estimó un $R R=1.9$.

La determinación de la concentración de azoados pre y posquirúrgica evidenció disminución de los valores después de la corrección del prolapso de órganos pélvicos (Cuadro 2).

Los estudios de control ecográfico, efectuados tres meses después de la cirugía de prolapso

Cuadro 1. Localización y grado de hidronefrosis en pacientes con prolapso de órganos pélvicos avanzado.

\begin{tabular}{|l|c|c|}
\hline Hidronefrosis & Grado & (n) \\
\hline Bilateral & Grado I & 1 \\
& Grado II & 5 \\
\hline \multirow{2}{*}{ Derecha } & Grado III & - \\
& Grado I & 1 \\
& Grado II & - \\
\hline Izquierda & Grado III & - \\
\hline Total & Grado I & - \\
\hline & Grado II & 1 \\
\hline
\end{tabular}


Cuadro 2. Concentración de azoados pre y posquirúrgicos en la corrección del prolapso de órganos pélvicos.

\begin{tabular}{l|c|c|c|c|c|}
\hline \multirow{2}{*}{ Relación de la concentración de azoados } & \multicolumn{2}{|c|}{ Estudio prequirúrgico } & \multicolumn{2}{|c|}{ Estudio posquirúrgico } & \multirow{2}{*}{ t de Student } \\
\cline { 2 - 5 } & Media & DE & Media & DE & p $<0.05$ \\
\hline Creatinina & 0.78 & 0.16 & 0.65 & 0.04 & $\mathrm{p}<0.05$ \\
\hline BUN & 17.6 & 5.70 & 14.6 & 2.39 & $\mathrm{p}<0.05$ \\
\hline Urea & 35.6 & 14.26 & 24.8 & 3.29 &
\end{tabular}

de órganos pélvicos, mostraron curación total de la hidronefrosis en $78 \%$ de los casos y parcial en $22 \%$, con reducción estadísticamente significativa $(p=0.046)$. Estas pacientes tenían antecedente de hidronefrosis bilateral grado II y en el control posterior a 3 meses de seguimiento reportaron hidronefrosis unilateral grado $\mathrm{I}$.

\section{DISCUSIÓN}

En relación con los antecedentes ginecoobstétricos y asociación de factores de riesgo de prolapso de órganos pélvicos, encontramos 85\% de pacientes multíparas (media de 7.08), dato similar al de diversos estudios, ${ }^{1}$ como el obtenido en la investigación de Fritel y su grupo, ${ }^{3}$ quienes señalan que el riesgo de prolapso de órganos pélvicos aumenta progresivamente en pacientes con dos partos, incluso el ensayo de Progetto Menopausa Italia Study Group reportó mayor riesgo en mujeres con 3 o más partos..$^{14,15}$

Respecto del parto instrumentado, $8 / 40$ pacientes refirieron uso de fórceps; sin embargo, en ningún caso se estableció el diagnóstico de hidronefrosis. ${ }^{1}$

De acuerdo con los datos de este estudio, 85\% de las pacientes se reportaron con sobrepeso y obesidad. Este resultado coincide con estudios internacionales que evidencian que las mujeres obesas tienen 1.7 más riesgo de sufrir prolapso de órganos pélvicos. ${ }^{1,15}$
La hidronefrosis aumenta significativamente con la gravedad del prolapso de órganos pélvicos. La hidronefrosis en pacientes con prolapso de órganos pélvicos avanzado se debe a la angulación de los uréteres por compresión extrínseca del útero y en mujeres con prolapso de la bóveda vaginal se origina debilitamiento y desintegración de los ligamentos cardinales poshisterectomía. .,10,11 $^{2}$

La prevalencia de hidronefrosis en pacientes con prolapso de órganos pélvicos fue de $22.5 \%$, mucho mayor a la reportada en otros estudios que señalan una variación entre 7 y $17 \%{ }^{6,10,11}$

De las 40 pacientes diagnosticadas con prolapso de órganos pélvicos grados III y IV se registraron 6 casos con hallazgos fortuitos en la ecografía renal: 2 con doble sistema colector, 2 con quiste renal simple y 2 con microlitiasis.

El riesgo de padecer hidronefrosis en pacientes con prolapso avanzado grado IV fue 2.6 veces más alto respecto de mujeres con prolapso grado IIIAa, Ba. Este hallazgo demuestra que a mayor grado de prolapso mayor predisposición a la hidronefrosis.

Al evaluar la concentración de azoados pre y posquirúrgicos en pacientes con hidronefrosis se observó disminución de creatinina, BUN y urea, lo que sugiere que la cirugía para corrección del prolapso de órganos pélvicos es una estrategia efectiva. ${ }^{1,12}$ 
El control ecográfico renal (tres meses después del procedimiento quirúrgico) evidenció la curación total de la hidronefrosis en la mayoría de las pacientes (de localización bilateral grado II disminuyó a unilateral grado I).

\section{REFERENCIAS}

1. Mark D. Walters, Mickey M. Karram, Uroginecología y cirugía reconstructiva de la pelvis. $3 \underline{a}$ ed. Barcelona: Elsevier Masson, 2014;17-29, 58-86.

2. Beverly CM, Walters MD, Weber AM, Piedmonte MR, Ballard LA. Prevalence of hydronephrosis in patients undergoing surgery for pelvic organ prolapse. Obstet Gynecol 1997;90(1);37-41.

3. Fritel X, Varnoux N, Zins M, Breart G, Ringa V. Symptomatic pelvic organ prolapse at midlife, quality of life, and risk factor. Obstet Gynecol 2009;113(3):609-616.

4. Kenton K, Brubaker L, Eckler K. Pelvic organ prolapse in women: Surgical repair of apical prolapse (uterine or vaginal vault prolapse). Update: Apr 24, 2017 [en línea]. Dirección URL: <https://www.uptodate.com/contents/ pelvic-organ-prolapse-in-women-surgical-repair-of-apicalprolapse-uterine-or-vaginal-vault-prolapse>.

5. Palma P, Dávila H. Uroginecología. 1a ed. Buenos Aires: Confederación Americana de Urología, 2006;171-176.

6. Bump RC, Mattiasson A, Bo K, Brubaker LP, Delancey JO, et al. The standardization of terminology of female pelvic organ prolapsed and pelvic floor disjunction. Am J Obstet Gynecol 1996;175(1):10-17.
7. Weber AM, Abrams P, Brubaker G, Cundiff G, et al. The Standardization of Terminology for Researchers in Female Pelvic Floor Disorders. Int Urogynecol J Pelvic Floor Dysfunct 2001;12(3):178-186.

8. Hui SY, Chan SC, Lam SY, Lau TK, Chung KH. A prospective study on the prevalence of hydronephrosis in women with pelvic organ prolapse and their outcomes after treatment. Int Urogynecol J 2011;22(12):1529-34.

9. Gemer O, Bergman M, Segal S. Prevalence of hydronephrosis in patients with genital prolapse. Eur J Ginecol Reprod Biol 1999;86(1):11-13.

10. Charles M. Beverly CM, Mark D, Walters MD, et al. Prevalence of hydronephrosis in patients undergoing surgery for pelvic organ prolapse. Obstet Gynecol 1997;90:37-41.

11. Moore S, Bailey RR, Maling TM, Little PJ. Urinary tract obstruction and renal failure due to uterine prolapse. $\mathrm{N}$ Z Med J 1978;87:429-31.

12. McAninch WJ, Lee FT. Smith y Tanago. Urología general. 18a ed. México: McGraw Hill Interamericana, 2014;170194.

13. Programa de Estadísticas Epidemiológicas de Código Abierto para Salud Pública (OpenEpi) versión 3.01. 2017 [en línea]. Dirección URL: <http://www.openepi.com/ Menu/OE_Menu.htm>.

14. VI Trobada de Comares de la Comunitat Valenciana Qualitat per a la dona davant el no mil lenni. PONENCIES. Generalitat valenciana Conselleria de sanitat 2003. [en línea]. Dirección URL: <http://publicaciones.san.gva.es/ publicaciones/documentos/V.2369-2003.pdf>.

15. Kang $\mathrm{H}$, et al. Obstructive anuria resulting from total uterine prolapsed: A case report. J Women's Med 2010;3(4):174-176. 